\title{
Tooth loss and associated self-rated health and psychological and subjective wellbeing among community-dwelling older adults: A cross-sectional study in India
}

\author{
T. Muhammad(1) and Shobhit Srivastava* (1)
}

\begin{abstract}
Background: Losing teeth has been considered as part of normal aging. However, in developing countries, tooth loss among older adults is shown to be more negatively associated with self-image and quality of life compared to their western counterparts. This study examines the association of tooth loss with self-rated health and psychological and subjective wellbeing among older adults in India.

Methods: Data were derived from the "Building Knowledge Base on Population Ageing in India" (BKPAI) survey which was carried out in 2011. The final sample size for the analysis was 9231 older adults. Descriptive statistics and bivariate analysis along with binary logistic regression analysis were conducted to fulfil the objective of the study.

Results: A proportion of $12.3 \%$ of older adults reported complete tooth loss. It was found that older adults who reported tooth loss were 2.38 times significantly more likely to have poor self-rated health (SRH) [2.38; Cl: 1.99,2.83] than older adults who did not report tooth loss. The odds of low psychological health were high among older adults who suffered from tooth loss than their counterparts [OR: 1.59; Cl: 1.33,1.91]. Older adults who reported tooth loss had $65 \%$ significantly higher odds of low subjective well-being than older adults who did not report tooth loss [OR: 1.65; Cl: $1.38,1.97]$.

Conclusion: Complete loss of teeth is associated with older individuals' poor SRH as well as low psychological and subjective well-being, but such a consequence is avoidable by practising the efforts to maintain good oral health.
\end{abstract}

Keywords: Tooth loss, Self-assessed health, Older adults, India

\section{Background}

Losing teeth progressively has been considered as part of normal aging [1]. However, in developing countries, tooth loss among older adults is shown to be more negatively associated with self-image and quality of life compared to their western counterparts [2,3]. Study reported that quite a few study participants discussed tooth loss

*Correspondence: shobhitsrivastava889@gmail.com International Institute for Population Sciences, Mumbai, Maharashtra 400088, India with their family and friends showing the society's perception of tooth loss as a social stigma despite the acceptance of tooth loss as normal aging procedure in western countries [2].

Findings of a study with 85-year-old participants indicated that older adults with more than 20 teeth had better subjective physical health than those who had less than 19 teeth [4]. A recent large population-based survey indicates that even loss of a few teeth may indicate an increased risk of cardiovascular diseases, diabetes, or all-cause mortality among older adults [5]. Furthermore, 
edentulism or complete loss of teeth significantly affects health related quality of life in older adults and the use of dental restorations do not improve their perceived quality of life [6]. Results from a review of 35 studies suggest that tooth loss is associated with unfavourable oral health-related quality of life (OHQoL) among older adults [7]. Significant associations between measures of oral-health problems, pain, and disability and three broader measures of psychological well-being were also revealed. Older adults in a study who rated their oral health as poor had poor self-rated general health than their counterparts who rated their oral health favourably [8].

Previous studies suggest that loss of teeth can also affect older people's ability to interrelate with others and can have a considerable impact on their lifestyle due to problems with communication in family and social interactions, causing isolation and depression [9-11]. A growing body of literature shows that physical fitness, psychological well-being and health behaviours such as exercise, alcohol consumption, smoking and obesity are associated with self-rated health (SRH) [12, 13]. Participation in exercise, balanced diet and non-smoking over the time predicted good SRH among older adults at follow-up [14]. Moreover, general health and oral health among older population were associated, although oral health impact was only associated with general health for those with more health problems, indicating that those in worse health suffer more problems from tooth loss $[8$, 15].

The loss of teeth that results in low self-esteem and poor performance of the individual in society proved to have a significant association with social participation [16]. Previous research has documented the effect of complete tooth loss or edentulism on facial appearance, speech, and eating that may have an impact on mental health and well-being through consequences such as low self-esteem, and decline in social activities due to embarrassment $[16,17]$. Studies have also examined the sociodemographic and health determinants of tooth loss and edentulism among older population in India [18-21]. On the other hand, the challenges to accessing dental care services including awareness, financial barriers, traditional beliefs, trust and convenience were well documented in prior research $[22,23]$.

Since dental care in India as in any other developing countries is considered entirely as a private matter at the expense of patients depending on their subjective considerations, few data is available and the studies on association of tooth loss with the health outcomes of older adults are scant. Since dentition status provides information pertinent to older adults' general health, we in this study examine the association of tooth loss with the subjective assessment of health outcomes among older adults in India. The study hypothesised that there is a significant association of tooth loss with subjective assessment of health among older adults in India.

\section{Methods \\ Data}

Data for this study are derived from the BKPAI survey (Building Knowledge Base on Population Ageing in India). The survey was carried out in India in 2011 [24]. A primary survey was conducted in seven states of India (Himachal Pradesh, Punjab, West Bengal, Odisha, Maharashtra, Kerala and Tamil Nadu), that covered a total of 9852 older adults from 8329 households in rural and urban areas [24]. The surveyed states have a higher percentage of the $60+$ population compared to the national average and these states also represent all regions of the country [24]. The individual questionnaire was used which covers the socio-demographic profile, work history, and benefit, income, and assets, living arrangement, social activities, the health status of older adults and social security related question [24]. The BKPAI sample design entails a two-stage probability sampling, where first, villages were classified into different strata on the basis of population size, and the number of PSUs (Primary sampling units) to be selected was determined in proportion to the population size of each stratum. Using probability proportional to population size (PPS) technique, the PSUs have been chosen, and within each selected PSU, households of older adults were selected through systematic sampling. A similar procedure was applied in drawing samples from urban areas [24]. Because this was a study of the elderly, the sample size was split evenly across urban and rural locations, regardless of the proportion of the population in each. The study included 80 PSUs (villages or urban wards) 40 urban and an equal number of rural - with 16 elderly households per PSU. The questionnaires for each state were bilingual, with questions in both the primary language of the states and English. The final sample size for the analysis was 9231 older adults. The study protocol is performed in accordance with the relevant guidelines. The ethical approval for the study was obtained from the university of Southampton and written informed consent was obtained from the human participants in the study.

\section{Variable description \\ Outcome variables}

In India, study found that SRH has a satisfactory construct validity which is even stronger than that in an advanced country showing its association with different health dimensions [25]. SRH in the current study have a scale of 1 to 5, "excellent, very good, good, fair and poor" 
and was categorized as 0 "good" (representing good, very good and excellent) and 1 "poor" (representing poor or fair) [26]. The 12-item version of the General Health Questionnaire (GHQ-12) was used as a measure of low psychological health. The GHQ-12 is an influential and reliable self-reported screening tool commonly used for identifying the non-specific and minor psychiatric disorder in the general population [27, 28]. Psychological health was having a scale of 0 to 12 on the basis of experiencing stressful symptoms and was recoded as 0 "high" (representing 6+ scores) and 1 "low" (representing score 5 and less) $[29,30]$. The low psychological health represents lower levels of psychological health or psychological distress among older adults (Cronbach's alpha: 0.90) [31].

The 9-item subjective well-being (SWB) questionnaire was used to measure low subjective well-being. Subjective well-being have a scale of 0 to 9 and was categorized as 0 "high" experiencing better experience (representing $6+$ scores) and 1 "low" experiencing negative experience (representing score 5 and less) [32]. Twelve questions on psychological health and nine questions on subjective well-being were asked to assess the outcome variables. All the questions were asked on Likert scales and were recoded and used accordingly as per literature [26]. The low subjective well-being represents lower levels of subjective well-being among older adults (Cronbach alpha: 0.93) [12].

\section{Explanatory variables}

The main explanatory variable for the current study is complete loss of teeth (permanent). The variable was assessed using the question asked under the chronic morbidities regarding the 'loss of all natural teeth' which was categorized as no and yes.

Smoking tobacco, chewing tobacco and Alcohol consumption was categorized as no and yes. Ability to do activities of daily living (ADL) was having a scale of 0 to 6 where in it represents higher the score higher the independence. A score of was categorized as 0 "no" which represents full independence and 5 and less was categorized as 1 "yes" which represents not fully independent to do activities of daily living (Cronbach Alpha: 0.93) [12]. Ability to do instrumental activities of daily living (IADL) was having a scale of 0 to 8 representing higher the score higher the independence. A score of $6+$ was categorized as 0 "no" representing high IADL and score of 5 and less was recoded as 1 "yes" representing low IADL $[12,33]$.

Age was categorized as 60-69, 70-79 and 80+years. Sex was categorized as male and female. Marital status was categorized as not in union "included never married, widowed, divorced and separated" and currently in union. Educational status was categorized as no schooling, below 5 years of schooling, 6-10years of schooling and 11 and above years of schooling. Working status was categorized as no and yes. The reference period was last 12 months. Living arrangement was categorized as living alone, with spouse, with children and other. Wealth quintile was computed using 30 household assets and was divided into 5 quintiles as poorest, poorer, middle, richer, richest. Religion was categorized as Hindu, Muslim, Sikh and others. Caste was categorized as Scheduled Caste, Scheduled Tribes, Other Backward Class and others. Place of Residence was categorized as rural and urban. Data for seven states was available in the data as mentioned in the data section.

\section{Statistical analysis}

Descriptive statistics and bivariate analysis were used to find the preliminary results. Further, binary logistic regression analysis [34] was used to fulfil the objective of the study. The outcome variable was SRH coded as 0 "good" and 1 "poor", low psychological health recoded as 0 "high" and 1 "low" and subjective well-being recoded as 0 "high" and 1 "low". The results were presented in the form of adjusted odds ratio (AOR) with a $5 \%$ significance level.

The model [34] is usually put into a more compact form as follows:

$$
\ln \left(\frac{P_{i}}{1-P_{i}}\right)=\beta_{0}+\beta_{1} x_{1}+\cdots+\beta_{M} x_{m-1},
$$

Where $\beta_{0}, \ldots ., \beta_{M}$ are regression coefficients indicating the relative effect of a particular explanatory variable on the outcomes. These coefficients change as per the context in the analysis in the study [34]. Variance inflation factor (VIF) [35] was calculated to measure multi-collinearity among the variables and it was revealed from the results that there was no evidence of multi-collinearity among the variables. Additionally, svyset command was used to control the analysis for complex survey design and individual weight present in the dataset was used to make the estimates representative.

\section{Results}

Socio-economic and demographic profile of older adults were described in Table 1 . About $12.3 \%$ of older adults suffer from tooth loss. Nearly 15, 22 and $8 \%$ of older adult's smoke tobacco, chew tobacco and consume alcohol. About $64 \%$ of older adults suffer from one or more chronic diseases. Almost $8 \%$ and $57 \%$ of older adults suffers from ADL and IADL. Nearly one-tenth of older adults were from age group 80 years and above. About $53 \%$ of older adults are female and $47 \%$ are male. Almost $61 \%$ of the older population was currently in union. 
Table 1 Socio-economic and demographic profile of older adults

\begin{tabular}{|c|c|c|}
\hline Background factors & Sample & Percentage \\
\hline \multicolumn{3}{|l|}{ Tooth loss } \\
\hline No & 8095 & 87.7 \\
\hline Yes & 1136 & 12.3 \\
\hline \multicolumn{3}{|l|}{ Smoking tobacco } \\
\hline No & 7809 & 84.6 \\
\hline Yes & 1422 & 15.4 \\
\hline \multicolumn{3}{|l|}{ Chewing tobacco } \\
\hline No & 7228 & 78.3 \\
\hline Yes & 2003 & 21.7 \\
\hline \multicolumn{3}{|l|}{ Alcohol consumption } \\
\hline No & 8525 & 92.4 \\
\hline Yes & 706 & 7.7 \\
\hline \multicolumn{3}{|l|}{ Chronic diseases } \\
\hline No & 3268 & 35.4 \\
\hline Yes & 5963 & 64.6 \\
\hline \multicolumn{3}{|l|}{ Difficulty in ADL } \\
\hline High & 8541 & 92.5 \\
\hline Low & 690 & 7.5 \\
\hline \multicolumn{3}{|l|}{ Difficulty in IADL } \\
\hline High & 4008 & 43.4 \\
\hline Low & 5223 & 56.6 \\
\hline \multicolumn{3}{|l|}{ Age (years) } \\
\hline $60-69$ & 5704 & 61.8 \\
\hline 70-79 & 2536 & 27.5 \\
\hline $80+$ & 991 & 10.7 \\
\hline \multicolumn{3}{|l|}{ Sex } \\
\hline Male & 4372 & 47.4 \\
\hline Female & 4859 & 52.6 \\
\hline \multicolumn{3}{|l|}{ Marital Status } \\
\hline Not in union & 3649 & 39.5 \\
\hline Currently in union & 5582 & 60.5 \\
\hline \multicolumn{3}{|l|}{ Education } \\
\hline No education & 4684 & 50.7 \\
\hline Below 5 years & 1900 & 20.6 \\
\hline 6-10years & 2086 & 22.6 \\
\hline $11+$ years & 562 & 6.1 \\
\hline \multicolumn{3}{|c|}{ Working status (last one year) } \\
\hline No & 6212 & 67.3 \\
\hline Yes & 2223 & 24.1 \\
\hline Retired & 796 & 8.6 \\
\hline \multicolumn{3}{|l|}{ Living arrangement } \\
\hline Alone & 547 & 5.9 \\
\hline With spouse & 1467 & 15.9 \\
\hline With children & 6493 & 70.3 \\
\hline Others & 725 & 7.9 \\
\hline \multicolumn{3}{|l|}{ Wealth quintile } \\
\hline Poorest & 2169 & 23.5 \\
\hline Poorer & 2029 & 22.0 \\
\hline Middle & 1913 & 20.7 \\
\hline
\end{tabular}

Table 1 (continued)

\begin{tabular}{|c|c|c|}
\hline Background factors & Sample & Percentage \\
\hline Richer & 1720 & 18.6 \\
\hline Richest & 1399 & 15.2 \\
\hline \multicolumn{3}{|l|}{ Religion } \\
\hline Hindu & 7324 & 79.3 \\
\hline Muslim & 651 & 7.1 \\
\hline Sikh & 870 & 9.4 \\
\hline Others & 386 & 4.2 \\
\hline \multicolumn{3}{|l|}{ Caste } \\
\hline Scheduled Caste & 1911 & 20.7 \\
\hline Scheduled Tribe & 515 & 5.6 \\
\hline Other Backward Class & 3364 & 36.4 \\
\hline Others & 3441 & 37.3 \\
\hline \multicolumn{3}{|l|}{ Residence } \\
\hline Rural & 6827 & 74.0 \\
\hline Urban & 2404 & 26.0 \\
\hline \multicolumn{3}{|l|}{ State } \\
\hline Himachal Pradesh & 1471 & 15.9 \\
\hline Punjab & 1279 & 13.9 \\
\hline West Bengal & 1128 & 12.2 \\
\hline Orissa & 1454 & 15.8 \\
\hline Maharashtra & 1229 & 13.3 \\
\hline Kerala & 1341 & 14.5 \\
\hline Tamil Nadu & 1330 & 14.4 \\
\hline Total & 9231 & 100.0 \\
\hline
\end{tabular}

$A D L$ Activities of Daily Living, IADL Instrumental Activities of Daily Living

Surprisingly, half of the older adults had no education at all whereas $6 \%$ had 11 and more years of education. About 9\% of older adults were retired at the time of survey. Nearly $6 \%$ of the older adults were living alone and $16 \%$ were living with their spouse. About one-fourth of the older adults belong to poorest wealth status. Nearly 8 in 10 older adults were from Hindu religion and 2 in 10 from Scheduled Caste category. About one-fourth of the older adults live in urban areas.

Figure 1 depicts percentage of tooth loss among older adults with poor SRH, low psychological health and low subjective well-being. The prevalence of poor SRH (80.1\%), low psychological health (27.4\%) and low subjective well-being (32.6\%) was high among older adults who suffered from tooth loss.

Table 2 represents percentage of older adults reporting poor SRH, low psychological health and low subjective well-being by background characteristic. Prevalence of poor SRH was high among older adults who smoke tobacco $(60 \%)$, chew tobacco $(57 \%)$, had chronic disease (63\%) and with low ADL (85\%) and IADL (63\%). Prevalence of low psychological health was high among older adults who chew tobacco (30\%), had chronic disease 


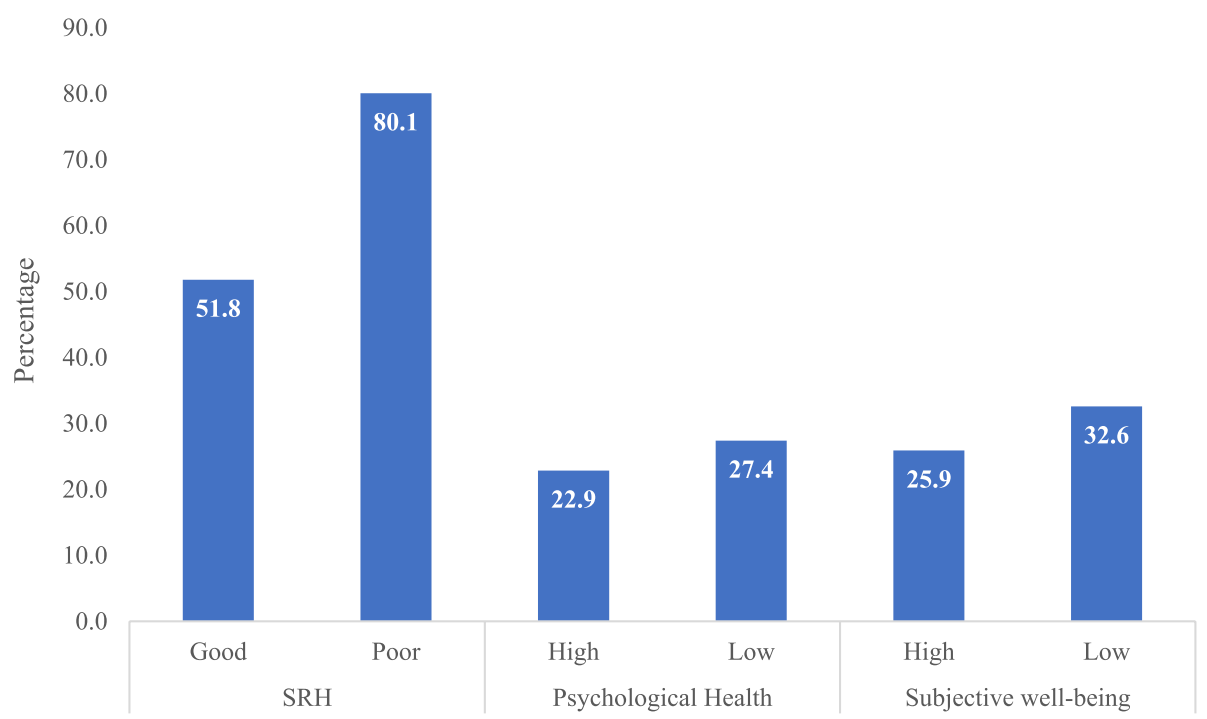

Fig. 1 Percentage of older adults suffering from tooth loss with poor SRH, low psychological health and low subjective well-being

(25\%) and with low ADL (51\%) and IADL (30\%). Prevalence of low subjective well-being was high among older adults who chew tobacco (34\%), had chronic disease (29\%) and with low ADL (55\%) and IADL (35\%). Apart from that poor SRH, low psychological health and low subjective well-being was significantly associated with age, gender, marital status, educational status, working status, living arrangement, wealth status, religion, caste and residential status.

Table 3 reveals logistic regression estimates for poor $\mathrm{SRH}$, low psychological health and low subjective wellbeing among older adults. The regression estimates were adjusted for other potential factors that affect the outcome variables as well. It was found that older adults who suffered from tooth loss were 2.38 times significantly more likely to report poor SRH [OR: 2.38; CI: 1.99,2.83] than the older adults who did not suffered from tooth loss. The odds for low psychological health was high among older adults who suffered from tooth loss than their counterparts [OR: 1.59 ; CI: $1.33,1.91]$. Older adults who suffers from tooth loss had $65 \%$ significantly higher likelihood to suffer from low subjective well-being than older adults who did not suffered from tooth loss [OR: 1.65; CI: 1.38,1.97].

\section{Discussion}

Maintaining good oral health is a key to present an older adult as a healthy person and improvise his/her longevity and wellbeing [36]. In the present study, tooth loss was encountered in $12.3 \%$ of the older participants. The low prevalence of tooth loss in low income countries may be related to low prevalence of dental caries due to consumption of non-refined carbohydrates [37].

The findings from the bivariate and multivariate analyses of tooth loss with measures of SRH, psychological health and subjective well-being as dependent variables were remarkably similar. Regardless of the direction of the association between oral status and health outcomes, analysis of our data indicates that poor oral health, poorer $\mathrm{SRH}$, psychological health and subjective well-being coexist among older adults. Similar finding pertaining to the present study found in the past literature indicating that the tooth loss in negatively associated with general health status and overall quality of life [37-40]. Loss of teeth also means loss of aesthetics in facial profile and personality, which does affect the social performance and ability of the individual to form social relations and low levels of well-being [17]. Further, it was also shown that the consequences of tooth loss that influence chewing ability, food intake and nutritional status, are complex leading to several problems in old age, including chronic diseases, functional disabilities, psychological and social factors, and lowered socioeconomic status [41, 42].

A review of literature reveals that poor health and disability are associated with low SWB at all ages and the health status is a strongest predictor of SWB during late life [43]. Consistently, our study also found that those who reported chronic diseases or low ADL or low IADL had poor SRH and low psychological and subjective well-being among the study sample. The performance of daily living activities and reduced functional dependency may strengthen feelings of autonomy and the ability to make personal decisions about how 
Table 2 Percentage of older adults reporting poor SRH, low psychological health and low subjective well-being

\begin{tabular}{|c|c|c|c|c|c|c|}
\hline \multirow[t]{2}{*}{ Background factors } & \multicolumn{2}{|c|}{ Poor SRH } & \multicolumn{2}{|c|}{ Low psychological health } & \multicolumn{2}{|c|}{$\begin{array}{l}\text { Low subjective well- } \\
\text { being }\end{array}$} \\
\hline & $\%$ & $p<0.05$ & $\%$ & $p<0.05$ & $\%$ & $p<0.05$ \\
\hline Smoking tobacco & & 0.046 & & 0.936 & & 0.455 \\
\hline No & 54.8 & & 23.7 & & 26.9 & \\
\hline Yes & 57.9 & & 22.1 & & 25.7 & \\
\hline Chewing tobacco & & 0.032 & & $<0.001$ & & $<0.001$ \\
\hline No & 54.9 & & 21.5 & & 24.8 & \\
\hline Yes & 56.8 & & 30.3 & & 33.7 & \\
\hline Alcohol consumption & & 0.093 & & 0.031 & & $<0.001$ \\
\hline No & 55.5 & & 23.7 & & 27.4 & \\
\hline Yes & 53.1 & & 19.8 & & 18.6 & \\
\hline Chronic diseases & & $<0.001$ & & $<0.001$ & & $<0.001$ \\
\hline No & 40.5 & & 20.0 & & 23.3 & \\
\hline Yes & 63.4 & & 25.3 & & 28.6 & \\
\hline Difficulty in ADL & & $<0.001$ & & $<0.001$ & & $<0.001$ \\
\hline High & 52.9 & & 21.2 & & 24.5 & \\
\hline Low & 84.7 & & 51.3 & & 54.8 & \\
\hline Difficulty in IADL & & $<0.001$ & & $<0.001$ & & $<0.001$ \\
\hline High & 45.5 & & 14.4 & & 16.1 & \\
\hline Low & 62.8 & & 30.4 & & 34.9 & \\
\hline Age (years) & & $<0.001$ & & $<0.001$ & & $<0.001$ \\
\hline $60-69$ & 49.6 & & 19.9 & & 23.2 & \\
\hline $70-79$ & 62.2 & & 27.0 & & 30.0 & \\
\hline $80+$ & 70.0 & & 34.9 & & 38.7 & \\
\hline Sex & & $<0.001$ & & $<0.001$ & & 0.048 \\
\hline Male & 51.9 & & 21.1 & & 23.9 & \\
\hline Female & 58.3 & & 25.5 & & 29.3 & \\
\hline Marital Status & & $<0.001$ & & $<0.001$ & & $<0.001$ \\
\hline Not in union & 61.3 & & 28.5 & & 32.9 & \\
\hline Currently in union & 51.3 & & 20.1 & & 22.7 & \\
\hline Education & & $<0.001$ & & $<0.001$ & & $<0.001$ \\
\hline No education & 61.0 & & 30.6 & & 35.5 & \\
\hline Below 5 years & 56.9 & & 22.3 & & 24.0 & \\
\hline 6-10years & 44.8 & & 12.5 & & 13.9 & \\
\hline $11+$ years & 41.1 & & 8.4 & & 10.3 & \\
\hline Working status (last one year) & & $<0.001$ & & $<0.001$ & & $<0.001$ \\
\hline No & 60.7 & & 27.1 & & 30.4 & \\
\hline Yes & 47.1 & & 19.4 & & 23.5 & \\
\hline Retired & 35.8 & & 6.2 & & 7.0 & \\
\hline Living arrangement & & $<0.001$ & & $<0.001$ & & $<0.001$ \\
\hline Alone & 56.7 & & 32.9 & & 39.7 & \\
\hline With spouse & 49.9 & & 20.7 & & 25.8 & \\
\hline With children & 55.8 & & 22.9 & & 25.4 & \\
\hline Others & 60.7 & & 26.3 & & 30.9 & \\
\hline Wealth quintile & & $<0.001$ & & $<0.001$ & & $<0.001$ \\
\hline Poorest & 61.8 & & 37.1 & & 47.3 & \\
\hline Poorer & 56.0 & & 29.6 & & 32.4 & \\
\hline Middle & 53.2 & & 19.7 & & 21.1 & \\
\hline Richer & 48.5 & & 14.7 & & 14.7 & \\
\hline
\end{tabular}


Table 2 (continued)

\begin{tabular}{|c|c|c|c|c|c|c|}
\hline \multirow[t]{2}{*}{ Background factors } & \multicolumn{2}{|c|}{ Poor SRH } & \multicolumn{2}{|c|}{ Low psychological health } & \multicolumn{2}{|c|}{$\begin{array}{l}\text { Low subjective well- } \\
\text { being }\end{array}$} \\
\hline & $\%$ & $p<0.05$ & $\%$ & $p<0.05$ & $\%$ & $p<0.05$ \\
\hline Richest & 55.2 & & 9.2 & & 9.3 & \\
\hline Religion & & $<0.001$ & & $<0.001$ & & $<0.001$ \\
\hline Hindu & 52.8 & & 25.7 & & 28.5 & \\
\hline Muslim & 66.3 & & 23.1 & & 29.9 & \\
\hline Sikh & 65.5 & & 7.8 & & 12.1 & \\
\hline Others & 61.4 & & 16.3 & & 21.6 & \\
\hline Caste & & $<0.001$ & & $<0.001$ & & $<0.001$ \\
\hline Scheduled Caste & 60.0 & & 28.0 & & 33.8 & \\
\hline Scheduled Tribe & 46.5 & & 32.4 & & 35.1 & \\
\hline Other Backward Class & 53.2 & & 25.7 & & 27.8 & \\
\hline Others & 56.0 & & 17.3 & & 20.5 & \\
\hline Residence & & $<0.001$ & & $<0.001$ & & $<0.001$ \\
\hline Rural & 56.9 & & 25.1 & & 28.3 & \\
\hline Urban & 50.8 & & 18.7 & & 22.4 & \\
\hline State & & $<0.001$ & & $<0.001$ & & $<0.001$ \\
\hline Himachal Pradesh & 46.0 & & 17.0 & & 15.1 & \\
\hline Punjab & 65.9 & & 7.2 & & 11.4 & \\
\hline West Bengal & 77.9 & & 29.3 & & 48.3 & \\
\hline Orissa & 47.5 & & 37.5 & & 35.3 & \\
\hline Maharashtra & 40.9 & & 22.7 & & 34.3 & \\
\hline Kerala & 67.1 & & 13.8 & & 14.8 & \\
\hline Tamil Nadu & 46.1 & & 36.2 & & 31.7 & \\
\hline
\end{tabular}

*if $p<0.05, \%$ percentage, SRH self-rated health, ADL Activities of Daily Living, IADL Instrumental Activities of Daily Living, $p$-value based on chi-square test

one should live in accordance with his/her own rules and preferences and that is fundamental to the mental health and well-being of older adults [44]. Moreover, the analysis also revealed a significant association between age and self-assessed health outcomes. This result was expected, considering the progressiveness of disability and dental caries among higher age groups, which account for many of the diseases.

Further, living with children and having greater number of children increase the likelihood of rotational living and shared responsibilities among adult children and caregiving for their older parents $[45,46]$. With social and familial support, older individuals generally feel loved and become confident when dealing with health problems and have higher self-esteem and wellbeing [47]. Concordantly, the present study also shows that older adults who are living with spouse, children or other relatives reported better psychological and subjective well-being compared to solo living older adults. Whereas, study also found that quality of an individual's relationships with spouse, children, and family rather than their presence was associated with psychological well-being [48].
Moreover, education and household economic status were found having significant negative relationship with poor SRH, low psychological health and low SWB. The finding is also consistent with previous studies showing that higher educational status and better economic conditions lead to higher levels of life satisfaction and wellbeing among older adults [49-51]. This is an interesting finding that indicates that lower-socio-economic group may not have either sufficient access or resources to seek dental treatment and leads to poor ratings of their health. In addition, educated older adults may have improved dental awareness, increased utilization of health facilities, proper oral hygiene habits that result in better oral health and well-being.

Studies of dental and oral problems among older individuals and their treatment seeking behaviour found that adequate access to medical and dental care can reduce premature morbidity and mortality, preserve function, and enhance overall quality of life [52, 53]. A study in India also found that less than $50 \%$ of edentulous and only $10 \%$ of partially edentulous older adults were wearing dentures due to the wide gap between the need and the services utilized [20]. 
Table 3 Logistic regression estimates for poor SRH, low psychological health and low subjective well-being among older adults

\begin{tabular}{|c|c|c|c|}
\hline Background factors & $\begin{array}{l}\text { Poor SRH } \\
\text { AOR }(95 \% \mathrm{Cl})\end{array}$ & $\begin{array}{l}\text { Low psychological health } \\
\text { AOR }(95 \% \mathrm{Cl})\end{array}$ & $\begin{array}{l}\text { Low subjective well-being } \\
\text { AOR }(95 \% \mathrm{Cl})\end{array}$ \\
\hline \multicolumn{4}{|l|}{ Tooth loss } \\
\hline No & Ref. & Ref. & Ref. \\
\hline Yes & $2.38 *(1.99,2.83)$ & $1.59 *(1.33,1.91)$ & $1.65^{*}(1.38,1.97)$ \\
\hline \multicolumn{4}{|l|}{ Smoking tobacco } \\
\hline No & Ref. & Ref. & Ref. \\
\hline Yes & $1.04(0.88,1.21)$ & $1.11(0.92,1.34)$ & $1.08(0.89,1.39)$ \\
\hline \multicolumn{4}{|l|}{ Chewing tobacco } \\
\hline No & Ref. & Ref. & Ref. \\
\hline Yes & $1.04(0.92,1.18)$ & $0.99(0.86,1.13)$ & $0.87^{*}(0.76,0.99)$ \\
\hline \multicolumn{4}{|l|}{ Alcohol consumption } \\
\hline No & Ref. & Ref. & Ref. \\
\hline Yes & $0.88(0.72,1.07)$ & $1.14(0.89,1.45)$ & $0.78(0.61,1)$ \\
\hline \multicolumn{4}{|l|}{ Chronic diseases } \\
\hline No & Ref. & Ref. & Ref. \\
\hline Yes & $2.17 *(1.91,2.34)$ & $1.57^{*}(1.39,1.79)$ & $1.40 *(1.31,1.67)$ \\
\hline \multicolumn{4}{|l|}{ Difficulty in ADL } \\
\hline High & Ref. & Ref. & Ref. \\
\hline Low & $2.44^{*}(1.94,3.06)$ & $2.27^{*}(1.88,2.74)$ & $2.61^{*}(2.15,3.14)$ \\
\hline \multicolumn{4}{|l|}{ Difficulty in IADL } \\
\hline High & Ref. & Ref. & Ref. \\
\hline Low & $1.63^{*}(1.47,1.81)$ & $1.68 *(1.47,1.91)$ & $1.72 *(1.52,1.94)$ \\
\hline \multicolumn{4}{|l|}{ Age (years) } \\
\hline $60-69$ & Ref. & Ref. & Ref. \\
\hline $70-79$ & $1.18 *(1.06,1.32)$ & $1.14(1,1.3)$ & $1.19 *(1.05,1.35)$ \\
\hline $80+$ & $1.18(0.99,1.41)$ & $1.19(0.98,1.43)$ & $1.26^{*}(1.04,1.51)$ \\
\hline \multicolumn{4}{|l|}{ Sex } \\
\hline Male & Ref. & Ref. & Ref. \\
\hline Female & $0.89(0.79,1.01)$ & $0.88(0.76,1.02)$ & $0.94(0.78,1.04)$ \\
\hline \multicolumn{4}{|l|}{ Marital Status } \\
\hline Not in union & Ref. & Ref. & Ref. \\
\hline Currently in union & $0.99(0.88,1.12)$ & $0.97(0.84,1.12)$ & $0.91(0.79,1.04)$ \\
\hline \multicolumn{4}{|l|}{ Education } \\
\hline No education & Ref. & Ref. & Ref. \\
\hline Below 5 years & $0.89(0.78,1.01)$ & $0.75^{*}(0.65,0.87)$ & $0.74^{*}(0.64,0.86)$ \\
\hline 6-10years & $0.69 *(0.6,0.79)$ & $0.48^{*}(0.4,0.57)$ & $0.53^{*}(0.45,0.63)$ \\
\hline $11+$ years & $0.60^{*}(0.48,0.75)$ & $0.51^{*}(0.36,0.71)$ & $0.51 *(0.37,0.7)$ \\
\hline \multicolumn{4}{|c|}{ Working status (last one year) } \\
\hline No & Ref. & Ref. & Ref. \\
\hline Yes & $0.77^{*}(0.68,0.88)$ & $0.81 *(0.7,0.94)$ & $0.83^{*}(0.71,0.95)$ \\
\hline Retired & $0.63^{*}(0.53,0.75)$ & $0.46^{*}(0.34,0.62)$ & $0.47^{*}(0.35,0.62)$ \\
\hline \multicolumn{4}{|l|}{ Living arrangement } \\
\hline Alone & Ref. & Ref. & Ref. \\
\hline With spouse & $0.99(0.78,1.26)$ & $0.61^{*}(0.46,0.79)$ & $0.82(0.61,1.04)$ \\
\hline With children & $1.01(0.82,1.25)$ & $0.73^{*}(0.58,0.92)$ & $0.71^{*}(0.57,0.89)$ \\
\hline Others & $0.93(0.72,1.21)$ & $0.93(0.69,1.24)$ & $0.89(0.67,1.18)$ \\
\hline \multicolumn{4}{|l|}{ Wealth quintile } \\
\hline Poorest & Ref. & Ref. & Ref. \\
\hline Poorer & $0.67^{*}(0.58,0.79)$ & $0.94(0.8,1.1)$ & $0.69^{*}(0.59,0.81)$ \\
\hline
\end{tabular}


Table 3 (continued)

\begin{tabular}{|c|c|c|c|}
\hline Background factors & $\begin{array}{l}\text { Poor SRH } \\
\text { AOR }(95 \% \mathrm{Cl})\end{array}$ & $\begin{array}{l}\text { Low psychological health } \\
\text { AOR }(95 \% \mathrm{Cl})\end{array}$ & $\begin{array}{l}\text { Low subjective well-being } \\
\text { AOR }(95 \% \mathrm{Cl})\end{array}$ \\
\hline Middle & $0.55^{*}(0.46,0.65)$ & $0.76^{*}(0.63,0.92)$ & $0.48^{*}(0.4,0.58)$ \\
\hline Richer & $0.49^{*}(0.41,0.59)$ & $0.65^{*}(0.52,0.8)$ & $0.41 *(0.34,0.51)$ \\
\hline Richest & $0.52^{*}(0.42,0.64)$ & $0.51 *(0.4,0.66)$ & $0.28^{*}(0.22,0.35)$ \\
\hline \multicolumn{4}{|l|}{ Religion } \\
\hline Hindu & Ref. & Ref. & Ref. \\
\hline Muslim & $1.02(0.81,1.23)$ & $1.16(0.92,1.46)$ & $1.08(0.87,1.35)$ \\
\hline Sikh & $1.03(0.81,1.31)$ & $1.08(0.67,1.48)$ & $1.07(0.76,1.51)$ \\
\hline Others & $1.11(0.87,1.43)$ & $0.95(0.69,1.31)$ & $1.11(0.82,1.49)$ \\
\hline \multicolumn{4}{|l|}{ Caste } \\
\hline Scheduled Caste & Ref. & Ref. & Ref. \\
\hline Scheduled Tribe & $0.82(0.65,1.04)$ & $0.84(0.65,1.08)$ & $0.81(0.64,1.04)$ \\
\hline Other Backward Class & $1.07(0.93,1.24)$ & $0.79 *(0.67,0.94)$ & $0.96(0.82,1.12)$ \\
\hline Others & $0.95(0.83,1.09)$ & $0.83^{*}(0.71,0.98)$ & $0.81^{*}(0.7,0.95)$ \\
\hline \multicolumn{4}{|l|}{ Residence } \\
\hline Rural & Ref. & Ref. & Ref. \\
\hline Urban & $1.01(0.91,1.12)$ & $0.99(0.87,1.12)$ & $1.17 *(1.04,1.32)$ \\
\hline \multicolumn{4}{|l|}{ State } \\
\hline Himachal Pradesh & Ref. & Ref. & Ref. \\
\hline Punjab & $2.06 *(1.67,2.55)$ & $0.38^{*}(0.27,0.54)$ & $0.72^{*}(0.52,0.99)$ \\
\hline West Bengal & $3.87^{*}(3 \cdot 18,4.71)$ & $1.92 *(1.53,2.41)$ & $4.88 *(3.91,6.11)$ \\
\hline Orissa & $0.76^{*}(0.63,0.92)$ & $2.34^{*}(1.86,2.95)$ & $2.13^{*}(1.69,2.68)$ \\
\hline Maharashtra & $0.73^{*}(0.61,0.88)$ & $1.63^{*}(1.29,2.06)$ & $3.31 *(2.63,4.14)$ \\
\hline Kerala & $3.01 *(2.48,3.66)$ & $1.08(0.82,1.41)$ & $1.36 *(1.05,1.77)$ \\
\hline Tamil Nadu & $1.23^{*}(1.01,1.54)$ & $5.07^{*}(3.98,6.46)$ & $2.77^{*}(2.17,3.52)$ \\
\hline R-square & 0.152 & 0.178 & 0.187 \\
\hline
\end{tabular}

Ref Reference, *if $p<0.05$, SRH self-rated health, ADL Activities of Daily Living, IADL Instrumental Activities of Daily Living, \% percentage, AOR Adjusted Odds Ratio

The study has certain limitations. The response for tooth loss was self-reported in nature. Furthermore, there are chances of misreporting of information, as the information on SRH, psychological health and SWB was self-reported. Similarly, the study findings are also limited by the possible effects of residual confounding in the current analyses. Although the data presented here support contemporary thinking concerning tooth loss among older population and their well-being, the findings should be interpreted with caution. Since the study was predominantly cross-sectional, the direction of the causality remains unresolved. The data were collected from seven states only. However, the population from these seven states was representative of the national sample. Apart from the above limitations, the study has strengths too. The study provides the pan India prevalence for tooth loss among older adults which was a missing part form recent literature in India. Moreover, the study associated tooth loss with overall health among older adults which was a much needed area to be focused in the country like
India where people associate tooth loss as a process of ageing and ignore the consequences that may worsen their overall health. Furthermore, longitudinal studies are warranted to broaden our current understanding of transitions in dental care during the late stages of life and its effect on well-being of older people.

\section{Conclusion}

Tooth loss continues to represent a major health care burden that is often neglected in countries like India. Loss of tooth in later years is associated with older individuals' poor SRH as well as low psychological and subjective well-being, but such a consequence is avoidable by practicing the efforts to maintain good oral health. Again, there is an increased need to understand the life context of the older individuals with less functional dentition in order to provide them with a better dental care through interventions capable of having a positive impact on the process of healthy ageing. 


\section{Abbreviations}

BKPAl: Building Knowledge Base on Population Ageing in India; SRH: Self-rated health; GHQ: General Health Questionnaire; SWB: Subjective well-being; ADL: Activities of daily living; IADL: Instrumental activities of daily living; OR: Odds Ratio; Cl: Confidence Interval.

\section{Acknowledgements}

Not applicable.

\section{Informed consent and guidelines}

Written informed consent was obtained from human participants in the study.

\section{Authors' contributions}

The concept was drafted by TM; SS contributed to the analysis design. Both authors contributed to the comprehensive writing of the article. Both the authors read and approved the final manuscript.

\section{Funding}

Authors did not receive any funding to carry out this research.

\section{Availability of data and materials}

The study utilises a secondary source of data that is freely available in public domain through request to http://www.isec.ac.in/.

\section{Declarations}

\section{Ethics approval and consent to participate}

The data is freely available in the public domain and survey agencies that conducted the field survey for the data collection have collected prior consent from the respondent. The ethical approval for obtained by university of South Hampton. To assess the dataset no ethical approval was required as the data was freely available through a request from http://www.isec.ac.in/.

\section{Consent for publication}

Not applicable.

\section{Competing interests}

The authors declare that they have no competing interests.

Received: 1 September 2021 Accepted: 20 December 2021

Published online: 04 January 2022

\section{References}

1. Shimazaki Y, Soh I, Saito T, et al. Influence of dentition status on physical disability, mental impairment, and mortality in institutionalized elderly people. J Dent Res. 2001;80:340-5.

2. Scott BJJ, Leung KCM, Davis DM, et al. A transcultural perspective on the emotional effect of tooth loss in complete denture wearers. Int J Prosthodont. 2001;14:461-5.

3. Fiske J, Davis DM, Leung KCM, et al. The emotional effects of tooth loss in partially dentate people attending prosthodontic clinics in dental schools in England. Scotland and Hong Kong: A preliminary investigation; 2001. p. 457-61.

4. Akifusa S, Soh I, Ansai T, et al. Relationship of number of remaining teeth to health-related quality of life in community-dwelling elderly. Gerodontology. 2005;22:91-7.

5. Liljestrand JM, Havulinna AS, Paju S, et al. Missing teeth predict incident cardiovascular events, diabetes, and death. J Dent Res. 2015;94:1055-62.

6. Cano-Gutiérrez C, Borda MG, Arciniegas AJ, et al. Edentulism and dental prostheses in the elderly: impact on quality of life measured with EuroQol--visual analog scale (EQ-VAS). Acta Odontol Latinoam. 2015:28:149-55

7. Gerritsen AE, Allen PF, Witter DJ, et al. Tooth loss and oral health-related quality of life: A systematic review and meta-analysis. Health Qual Life Outcomes. 2010;8:1-11.

8. Brennan DS, Teusner DN. Oral health impacts on self-rated general and oral health in a cross-sectional study of working age adults. Community Dent Oral Epidemiol. 2015;43:282-8.
9. Srisilapanan P, Sheiham A. The prevalence of dental impacts on daily performances in older people in Northern Thailand. Gerodontology. 2001:18:102-8.

10. Tyrovolas S, Koyanagi A, Panagiotakos DB, et al. Population prevalence of edentulism and its association with depression and self-rated health. Sci Rep. 2016;6:1-9.

11. Matsuyama $Y$, Jürges $H$, Dewey $M$, et al. Causal effect of tooth loss on depression: Evidence from a population-wide natural experiment in the USA. Epidemiol Psychiatr Sci Epub ahead of print. 2021. https://doi.org/ $10.1017 /$ S2045796021000287

12. Srivastava S, Muhammad T. Violence and associated health outcomes among older adults in India: A gendered perspective. SSM Popul Heal. 2020;12. Epub ahead of print. https://doi.org/10.1016/j.ssmph.2020. 100702.

13. Muhammad T, Maurya P. Gender differences in the association between perceived income sufficiency and self-rated health among older adults : A population-based study in India based study in India. J Women Aging. 2021;00:1-14.

14. Manderbacka K, Lundberg O, Martikainen P. Do risk factors and health behaviours contribute to self- ratings of health? Soc Sci Med. 1999;48:1713-20

15. Brennan DS, Singh KA. General health and oral health self-ratings, and impact of oral problems among older adults. Eur J Oral Sci. 2011;119:469-73.

16. Rodrigues SM, Oliveira AC, Vargas AMD, et al. Implications of edentulism on quality of life among elderly. Int J Environ Res Public Health. 2012;9:100-9.

17. Naik AV, Pai RC. Study of Emotional Effects of Tooth Loss in an Aging North Indian Community. ISRN Dent. 2011;2011:1-4.

18. Nagaraj E, Mankani N, Madalli P, et al. Socioeconomic factors and Complete edentulism in North Karnataka population. J Indian Prosthodont Soc. 2014;14:24-8.

19. Kailembo A, Preet R, Stewart WJ. Common risk factors and edentulism in adults, aged 50 years and over, in China, Ghana, India and South Africa: Results from the WHO Study on global AGEing and adult health (SAGE). BMC Oral Health. 2016;17. Epub ahead of print. https://doi.org/10.1186/ s12903-016-0256-2.

20. Bijjargi S, Chowdhary R. Geriatric dentistry: Is rethinking still required? A community-based survey in Indian population. Gerodontology. 2013;30:247-53.

21. Selvamani Y, Singh P. Association between Underweight and Edentulism among Older (50+) Men and Women in India. Ageing Int. 2020;45:315-26.

22. Li C, Yao NA. Socio-Economic Disparities in Dental Health and Dental Care Utilisation Among Older Chinese. Int Dent J. 2021;71:67-75.

23. Mittal $\mathrm{R}$, Wong ML, Koh GCH, et al. Factors affecting dental service utilisation among older Singaporeans eligible for subsidized dental care - A qualitative study. BMC Public Health. 2019;19:1-8.

24. UNFPA. Report on the status of elderly in selected states of India: Building a knowledge base on ageing in India. New Delhi; 2012.

25. Heinonen $\mathrm{H}$, Aro AR, Aalto A-M, et al. Is the Evaluation of the Global Quality of Life Determined by Emotional Status? Qual Life Res. 2004;13:1347-56.

26. Joe W, Perkins JM, Subramanian SV. Community involvement, trust, and health-related outcomes among older adults in India: A populationbased, multilevel, cross-sectional study. Age Ageing. 2019;48:87-93.

27. Goldberg DP, Gater R, Sartorius N, et al. The validity of two versions of the GHQ in the WHO study of mental illness in general health care. Psychol Med. 1997;27:191-7.

28. Hankins M. The reliability of the twelve-item general health questionnaire (GHQ-12) under realistic assumptions. BMC Public Health. 2008;8:1-7.

29. Jacob KS, Bhugra D, Mann AH. General health questionnaire - 12: psychometric properties and factor structure among Indian women living in the United Kingdom. Indian J Psychiatry. 1997;39:196-9.

30. Shidhaye R, Patel V. Association of socio-economic, gender and health factors with common mental disorders in women: A populationbased study of 5703 married rural women in India. Int J Epidemiol. 2010;39:1510-21.

31. Srivastava S, Purkayastha N, Chaurasia H, et al. Socioeconomic inequality in psychological distress among older adults in India : a decomposition analysis. BMC Psychiatry. 2021;21:1-15. 
32. Sell H, Nagpal R. Assessment of Subjective Well-being: The Subjective Well-Being Inventory (SUBI). World Health Organization Regional Health Paper, SEARO.

33. Sharma P, Maurya P, Muhammad T. Number of chronic conditions and associated functional limitations among older adults: cross-sectional findings from the longitudinal aging study in India. BMC Geriatr. 2021;21(1):1-12.

34. Osborne J, King JE. Binary Logistic Regression. In: Best Practices in Quantitative Methods: SAGE Publications, Inc: 2011. p. 358-84.

35. Marcoulides KM, Raykov T. Evaluation of Variance Inflation Factors in Regression Models Using Latent Variable Modeling Methods. Educ Psychol Meas. 2019;79:874-82.

36. Mary CM, Grover HS, Tandon S, et al. Gender-wise comparison of oral health-related quality of life and its relationship with periodontal status among the Indian elderly. J Indian Soc Periodontol. 2019;24:72-9.

37. Emami E, De Souza RF, Kabawat M, et al. The impact of edentulism on oral and general health. Int J Dent. 2013. Epub ahead of print 2013. https:// doi.org/10.1155/2013/498305.

38. Borda MG, Castellanos-Perilla N, Patiño JA, et al. Edentulism and its relationship with self-rated health: secondary analysis of the SABE Ecuador 2009 Study. Acta Odontol Latinoam. 2017;30:83-9.

39. Huang DL, Chan KCG, Young BA. Poor oral health and quality of life in older U.S. adults with diabetes mellitus. J Am Geriatr Soc. 2013;61:1782-8.

40. Locker D, Clarke M, Payne B. Self-perceived oral health status, psychological well-being, and life satisfaction in an older adult population. J Dent Res. 2000;79:970-5.

41. Walls AWG, Steele JG. The relationship between oral health and nutrition in older people. Mech Ageing Dev. 2004;125:853-7.

42. Nieuwenhuizen WF, Weenen $H$, Rigby $P$, et al. Older adults and patients in need of nutritional support : Review of current treatment options and factors influencing nutritional intake. Clin Nutr. 2010;29:160-9.

43. George LK. Still happy after all these years: Research frontiers on subjective well-being in later life. J Gerontol Ser B Psychol Sci Soc Sci. 2010;65 B:331-9.

44. Bojorquez-Chapela I, Manrique-Espinoza BS, Mejía-Arango S, et al. Effect of social capital and personal autonomy on the incidence of depressive symptoms in the elderly: Evidence from a longitudinal study in Mexico. Aging Ment Health. 2012;16:462-71.

45. Muhammad T, Srivastava S. Why Rotational Living Is Bad for Older Adults ? Evidence from a Cross- Sectional Study in India Why Rotational Living Is Bad for Older Adults ? Evidence from a Cross-Sectional Study in India. Epub ahead of print. 2020. https://doi.org/10.1007/s12062-020-09312-4.

46. Ugargol AP, Hutter I, James KS, et al. Care Needs and Caregivers: Associations and Effects of Living Arrangements on Caregiving to Older Adults in India. Ageing Int. 2016;41:193-213.

47. Tian Q. Intergeneration social support affects the subjective well-being of the elderly: Mediator roles of self-esteem and loneliness. J Health Psychol. 2016;21:1137-44.

48. Ryan AK, Willits FK. Family Ties, Physical Health, and Psychological WellBeing. J Aging Health. 2007;19(6):907-20.

49. Howell RT, Howell CJ. The Relation of Economic Status to Subjective Well-Being in Developing Countries: A Meta-Analysis. Psychol Bull. 2008;134:536-60.

50. Srivastava S, Chauhan S, Muhammad T, et al. Older adults' psychological and subjective well-being as a function of household decision making role: Evidence from cross-sectional survey in India. Clin Epidemiol Glob Heal. 2021;10:100676.

51. Muhammad T, Srivastava S, Sekher TV. Association of self-perceived income status with psychological distress and subjective well-being: a cross-sectional study among older adults in India. BMC Psychol. 2021;9:1-13.

52. Ahluwalia KP, Cheng B, Josephs PK, et al. Oral disease experience of older adults seeking oral health services. Gerodontology. 2010;27:96-103.

53. AlZarea BK. Dental and Oral Problem Patterns and Treatment Seeking Behavior of Geriatric Population. Open Dent J. 2017;11:230-6.

\section{Publisher's Note}

Springer Nature remains neutral with regard to jurisdictional claims in published maps and institutional affiliations.

Ready to submit your research? Choose BMC and benefit from:

- fast, convenient online submission

- thorough peer review by experienced researchers in your field

- rapid publication on acceptance

- support for research data, including large and complex data types

- gold Open Access which fosters wider collaboration and increased citations

- maximum visibility for your research: over 100M website views per year

At BMC, research is always in progress.

Learn more biomedcentral.com/submissions 